This is an electronic reprint of the original article. This reprint may differ from the original in pagination and typographic detail.

Author(s): Salonen, Jouni; Taskinen, Jouni

Title: $\quad$ Electrofishing as a new method to search for unknown populations of the endangered freshwater pearl mussel Margaritifera margaritifera

Year: $\quad 2017$

Version:

Please cite the original version:

Salonen, J., \& Taskinen, J. (2017). Electrofishing as a new method to search for unknown populations of the endangered freshwater pearl mussel Margaritifera margaritifera. Aquatic Conservation: Marine and Freshwater Ecosystems, 27(1), 115127. https://doi.org/10.1002/aqc.2667

All material supplied via JYX is protected by copyright and other intellectual property rights, and duplication or sale of all or part of any of the repository collections is not permitted, except that material may be duplicated by you for your research use or educational purposes in electronic or print form. You must obtain permission for any other use. Electronic or print copies may not be offered, whether for sale or otherwise to anyone who is not an authorised user. 


\section{Electrofishing as a new method to search for unknown populations of the endangered freshwater pearl mussel Margaritifera margaritifera}

Jouni K. Salonen and Jouni Taskinen *

Department of Biological and Environmental Science, University of Jyväskylä, P.O.

Box 35, FI-40014 University of Jyväskylä, Finland

* Correspondence to: Department of Biological and Environmental Science, University of Jyväskylä, P.O. Box 35, FI-40014 University of Jyväskylä, Finland. E-mail:

jouni.k.taskinen@jyu.fi

Running Head: Electrofishing to search for M. margaritifera

Keywords: brown trout; distribution; electrofishing; endangered species; freshwater pearl mussel; glochidia; occurrence; river
Abstract
1. The freshwater pearl mussel Margaritifera margaritifera is threatened throughout its Holarctic range, but the occurrence of this species is insufficiently mapped. For the conservation of $M$. margaritifera, it is important to identify populations more comprehensively.
2. Traditionally mussels have been searched for visually using techniques such as diving and aquascope, both of which are potentially time-consuming and demanding survey methods.
3. In this study, a new search method is presented. As glochidia of M. margaritifera are larval parasites on gills of salmonid fish, electrofishing and non-destructive examination of salmonids with the naked eye may reveal the presence of glochidia and therefore the occurrence of $M$. margaritifera in watercourses. This method was tested in both the field and laboratory in northern Finland.
4. In summer, when M. margaritifera glochidia were large, the status of salmonids being infected or uninfected by $M$. margaritifera was correctly identified with the naked 
eye with 62, 80, 88 and $93 \%$ accuracy in four streams sampled, $96 \%$ accuracy in the laboratory, and $100 \%$ accuracy in all cases when at least 20 glochidia per fish were present. Intensity of infection was also assessed successfully; a specifically tailored, qualitative abundance score correlated significantly with the real number of glochidia. However, during autumn with small glochidia freshly attached to fish, glochidia infection could be observed only under microscopic examination.

5. When the method was used in 40 previously incompletely surveyed tributaries, three M. margaritifera populations were found. The infection in salmonids was observed always with the naked eye, being subsequently confirmed microscopically. The existence of adult mussels in two of these rivers was also confirmed.

6. The results indicate that electrofishing and a relatively quick naked-eye check of salmonids provides a new, non-destructive, and potentially cost-effective way to search for new, previously unrecorded $M$. margaritifera populations.

\section{INTRODUCTION}

The freshwater pearl mussel, Margaritifera margaritifera, is a threatened bivalve mollusc which lives in pristine running waters in the Holarctic region and is often considered as an indicator of natural, undisturbed habitats (Geist, 2010). However, the occurrence of M. margaritifera is not precisely known within its range, with 'new', previously unknown and even remarkably large or genetically important populations still being found occasionally (Álvarez-Claudio et al., 2000; Reis, 2003; Ostrovsky and Popov, 2011; Oulasvirta, 2011; Varandas et al., 2013). Therefore, although M. margaritifera populations from extensively studied river systems are probably well documented, a considerable number of unknown populations may still exist in insufficiently surveyed streams and rivers (Cosgrove et al., 2000; Oulasvirta, 2011). In particular, the occurrence of $M$. margaritifera in remote areas of northernmost Europe has not been mapped thoroughly, and when information regarding its occurrence is available, the details are often sporadic, e.g. historical pearl fishing records or local, unconfirmed knowledge (Young and Williams, 1983b; Oulasvirta, 2011; Simon et al., 2015). To avoid the accidental disturbance of not yet recorded populations via e.g. forestry operations, ditching, or peat mining - activities that are widespread and causes 
of freshwater pearl mussel population extinctions especially in the north (Oulasvirta, 2011 ) - it is highly important to have detailed information on the distribution of $M$. margaritifera. In addition, there may also be a need to characterize the current status of M. margaritifera in rivers or river sections where the species has been reported in the past (Oulasvirta, 2011).

M. margaritifera has a complex life cycle (e.g. Young and Williams, 1984a; Bauer, 1987b; Hastie and Young, 2001; Geist et al., 2006), which includes up to almost one year in a parasitic phase on gills of a salmonid host fish, Atlantic salmon (Salmo salar) or brown trout (Salmo trutta). This is followed by a post-parasitic stage in which the juvenile mussel is completely burrowed in the river substratum for several years. After these critical stages, adult $M$. margaritifera can reportedly live more than 200 years (Ziuganov et al., 2000; Helama and Valovirta, 2008). Anthropogenic perturbations, including siltation, loss of habitats, pollution, loss of host fish, introduction of invasive species, and commercial exploitation have caused a substantial decline of freshwater mussels worldwide (Bauer, 1988; Williams et al., 1993; Lydeard et al., 2004). Many of these factors have been suggested to be the reasons for the decline of $M$. margaritifera, too, with the species now being extinct or close to extinction in many areas (Young and Williams, 1983b; Bauer, 1986, 1988; Cosgrove et al., 2000; Oulasvirta, 2011; Simon et al., 2015). At present, M. margaritifera is classified as critically endangered in Europe (Cuttelod et al., 2011HCN Red List of Threatened Species, 2013).

Today, mapping the occurrence of $M$. margaritifera consists of visual techniques like SCUBA diving, snorkeling, using an aquascope or underwater camera, or observing mussels visually from the shore or in a boat (Álvarez-Claudio et al., 2000; Reis, 2003; Cosgrove et al., 2000, 2007; Oulasvirta, 2011; Varandas et al., 2013; Simon et al., 2015). However, these methods can be time-consuming, and factors like dark or turbid water, boulder substrate, aggregated distribution of mussels, deep water or large areas of unsurveyed watercourses may limit their applicability (Young and Williams, 1983a; Álvarez-Claudio et al., 2000; Cosgrove et al., 2000; Strayer and Smith, 2003; Oulasvirta, 2011). Thus, alternative methods for determining the presence of mussels in unsurveyed watercourses would be welcome. Since M. margaritifera is dependent on a 
host fish to complete its life cycle, one such method could be capturing potential host fish individuals and examining them for M. margaritifera glochidia. The glochidia are relatively small (ca. $70 \mu \mathrm{m}$ ) at the beginning of the parasitic phase in autumn, but when fully developed, they are much larger $(400-500 \mu \mathrm{m})$ and possibly observable with the naked eye (e.g. Young and Williams, 1984b; Bauer and Vogel, 1987; Pekkarinen and Valovirta, 1996). Thus, it should be possible to detect the occurrence of $M$. margaritifera glochidia without killing the host fish for microscopic examination. Electrofishing is a widely used method to capture small salmonids non-destructively (Hudy, 1985; Bohlin et al., 1989), and is not harmful to mussels (Hastie and Boon, 2001). It is, therefore, possible that $M$. margaritifera glochidia can be seen by quickly looking into the gills of electrically caught and stunned, and afterwards released, host salmonids. Overall, this method could serve as a new, non-destructive way to search for undescribed freshwater pearl mussel populations.

An equivalent method of identifying $M$. margaritifera glochidia in fish caught by electrofishing was earlier developed and presented by Österling (2011). In that study, the intensity of $M$. margaritifera infection was estimated by photographing gills of anaesthetised brown trout, with a metal spatula inserted between its gill arches. The results indicated that a reliable estimate of the number of glochidia can be determined by examining photographs of fish gills (Österling, 2011). In addition, the method, including electrofishing, anaesthetising, and photographing was non-destructive given that the survival and growth of brown trout was not affected by these treatments (Österling, 2011). In the present study, the procedure of Österling (2011) is modified to develop a new technique for uncovering natural populations of $M$. margaritifera. First, it was tested whether the occurrence and the intensity of $M$. margaritifera infection in potential fish hosts could be reliably estimated quickly with the naked eye immediately after fish are caught by electrofishing. Secondly, the method was used in practice to search for previously unknown $M$. margaritifera populations in northern Finland.

\section{METHODS}

\section{Testing the method: finding $M$. margaritifera glochidia using the naked eye}


The method was first tested in four small streams in the River Iijoki catchment (14200 $\mathrm{km}^{2}$, draining to the Baltic Sea) in Finland, northern Europe (Figure 1). These rivers with average depth 0.22 to $0.63 \mathrm{~m}$ and width 1.1 to $4.6 \mathrm{~m}$ were previously confirmed to harbour freshwater pearl mussel. In 2011, the electrofishing was carried out close to the known mussel beds of the Rivers Jukuanoja (total river length $4.7 \mathrm{~km}$ ) and Koivuoja $(14.7 \mathrm{~km})$ five times during summer to assess the compatibility of the method to $M$. margaritifera glochidia of different sizes. Information about the life cycle of freshwater pearl mussel from these insufficiently investigated populations was also collected. In 2012-2013, the study sites were the Rivers Majovanoja (13.5 km) and Pahkaoja (2.4 $\mathrm{km}$ ) which were fished once in June, as the 2011 survey revealed that this is the optimal time to find salmonids infected by large $M$. margaritifera glochidia. The preliminary goal was to collect five juvenile brown trout or salmon individuals per river on each survey occasion, given that the young salmonids are the most suitable hosts for $M$. margaritifera (e.g. Young and Williams, 1984a; Hastie and Young, 2001; Österling and Wengström, 2015). However, because the salmonid populations in the rivers appeared not to be too numerous and the acquired licenses also restricted the number of fish to be sacrificed, the sample sizes were reduced (see Results).

The electrofishing was conducted using GeOmega FA4 or Paulsen FA4 device, and the total time spent at each site varied from 15 to 90 minutes. In 2011, each brown trout was quickly checked by one person and classified as being infected or uninfected by $M$. margaritifera using only the naked eye, through gently opening the operculum using wet rubber gloves so that the fish was not harmed and could have been quickly released. In 2012-2013, the intensity of $M$. margaritifera infection was assessed in the field by two or three independent observers. Each of them scored the intensity on each fish as 0 , $1,2,3,4$ or 5 , where 0 indicated no glochidia found, while 5 indicated a very high number of glochidia found (Figure 2). These procedures, taking only a few seconds, were conducted immediately after the fish was caught and still stunned by the electric shock. After these actions, each fish was killed and stored on ice. Later, the total length $(\mathrm{mm})$ of each fish was recorded and the number of M. margaritifera glochidia in their gills was determined microscopically. The length $(\mu \mathrm{m})$ of glochidia was determined by 
randomly picking 10 individuals per fish and measuring them using an ocular scale on the microscope.

The naked-eye scoring technique was also tested in laboratory using artificially infected, farmed brown trout. The one year old fish were exposed to $M$. margaritifera originating from the River Livojoki (Figure 1) in September 2014 at Konnevesi Research Station (University of Jyväskylä). Glochidia were collected by placing several adult mussels temporarily in a bucket with $5 \mathrm{~L}$ of water (see Young and Williams, 1984a; Bauer, 1987a), allowing them to release their glochidia naturally. Then a total of $1.5 \mathrm{~L}$ of glochidial suspension microscopically estimated to have approximately 180000 larvae were added to the $163 \mathrm{~L}$ tank containing 100 brown trout from the Rautalampi (Konnevesi) strain. In July 2015, the fish were scored for the intensity of $M$. margaritifera infection by two independent observers as outlined above.

An association between the mean of the naked-eye scores and the number of glochidia confirmed microscopically was analysed statistically with Spearman correlation analysis using IBM SPSS Statistics (version 20.0.2, IBM Corporation, New York, United States). Prior to this analysis, possible differences in the naked-eye scores between different observers were checked with Friedman test. River-level mean nakedeye scores for intensity of $M$. margaritifera infection were also created by first calculating the fish-level mean of the scores of two or three observers, and then calculating the total mean of these individual means within each river.

\section{Applying the method: searching for $M$. margaritifera populations using the electrofishing method}

The method was applied in June 2012 and June 2013 to 40 previously unsurveyed or incompletely surveyed rivers in the River Iijoki drainage (Figure 1). These rivers, potentially harbouring $M$. margaritifera, were selected for study after consultations with local experts who, for example, informed us about possible pearl fishing history in the area. Nonetheless, even the presence of salmonid fish was unknown in many of the rivers before the current study. Eight of the rivers were electrofished in both years, and 
in some rivers the fishing site was changed several times if salmonids were not found. The total time spent electrofishing per river varied from 30 minutes to 195 minutes, and the target was to catch five young salmonid per river. However, salmonids were not found in all rivers, while in some sites the fish density appeared to be high and catches were increased (see Results). After each salmonid catch, the intensity of $M$. margaritifera infection was quickly scored from 0 to 5 (Figure 2) by two or three observers as above. The infection status and number of glochidia infecting each fish was confirmed later in the laboratory, and if any M. margaritifera glochidia were found, the occurrence of adult mussels in the river was verified. Mean naked-eye score for each river was calculated as above, and mean intensity of infection for each river was calculated to represent the mean number of glochidia per infected fish.

\section{RESULTS}

\section{Testing the method: finding $M$. margaritifera glochidia using the naked eye}

In both the Rivers Jukuanoja and Koivuoja, M. margaritifera glochidia that had attached to fish in the previous year were found still on fish gills in June and July but not during August, indicating the excystment of glochidia had occurred between late July and early August (Table 1). In late August, a new glochidium generation was attached to fish in the River Jukuanoja, but not among fish in the River Koivuoja (Table $1)$.

In June and July, when glochidia were large (i.e. shortly before they had detached from their hosts) the status of brown trout as being infected or uninfected by $M$. margaritifera was correctly classified in 13 out of 14 (93\%) fish in the River Jukuanoja, and in 8 out of $13(62 \%)$ fish in the River Koivuoja (Table 1). No false positive records were obtained, and all the false negative assessments were among the fish carrying 1 to 19 glochidia. Thus, the naked-eye classification of fish was $100 \%$ correct for both rivers when there were at least 20 glochidia per fish (Table 1). The mean length of glochidia on each fish varied from 247 to $456 \mu \mathrm{m}$ in June-July (Table 1). However, when the next generation of glochidia had attached to fish in the River Jukuanoja at the end of August, 
each fish caught was misclassified as uninfected with the naked eye, although all of them were infected, most of them heavily (Table 1). The mean length of these "new" glochidia was $74-81 \mu \mathrm{m}$.

The catch from the Rivers Majovanoja and Pahkaoja in June 2012 and 2013 included 12 brown trout, with most of them carrying $M$. margaritifera glochidia of 202-296 $\mu \mathrm{m}$ in mean size (Table 2). Using two or three observers for each fish, the infection status was correctly classified in 12 out of $15(80 \%)$ cases in the River Majovanoja, 15 out of 17 $(88 \%)$ cases in the River Pahkaoja, and in $100 \%$ of cases when there were more than 4 glochidia per fish (Table 2). Moreover, the mean naked-eye scores correlated significantly $\left(r_{s}=0.864, p<0.001, n=12\right)$ with the numbers of glochidia confirmed microscopically (Table 2). There were no significant differences (Friedman test, $p=$ 0.472) in scores between different observers (Table 2). Furthermore, for individual fish, the mean of the naked-eye score values greater than 0.50 consistently identified $M$. margaritifera infection (Table 2). However, a mean score higher than 0 but less than or equal to 0.50 indicated a probability for a false positive classification (Table 2). For each river, the mean scores were much higher than 0.50; 2.20 for the River Majovanoja and 1.12 for the River Pahkaoja (Table 2).

In the laboratory experiment with artificially infected brown trout, glochidia were found in 11 of 40 fish, having a mean length of 339 to $409 \mu \mathrm{m}$ (Table 3). With two observers, the infection status was correctly classified in 77 out of 80 (96\%) cases and in $100 \%$ of cases where fish was carrying more than one larva (Table 3). The mean scores correlated significantly $\left(r_{s}=0.931, p<0.001, n=40\right)$ with the numbers of glochidia counted microscopically (Table 3 ). There were no significant differences between the scores of individual observers (Friedman test, $p=0.257$ ), and the mean of the scores greater than 0.50 identified the infected fish in each case (Table 3).

\section{Applying the method: searching for $M$. margaritifera populations using the electrofishing method}


Among the 40 rivers surveyed, brown trout were caught from 22 rivers, with a total catch of 141 individuals (Table 4). M. margaritifera infection was recorded on 10 fish in three rivers, and in each of the rivers the infection was observed also with the naked eye in the field (Table 4). Thus, the application of the new electrofishing method revealed three $M$. margaritifera populations from the Rivers Kisosjoki, Lukkarinoja and Kostonlammenoja (Figure 1, Table 4). The presence of adult mussels in the Rivers Kisosjoki and Lukkarinoja were verified later during summer 2012. In the River Kisosjoki the verification, using an aquascope and snorkel, took about six hours, and a total of 15 adult mussels were found $100 \mathrm{~m}$ to $1 \mathrm{~km}$ above the electrofishing site. In the River Lukkarinoja, 5000 mussels were found in two hours a few $\mathrm{km}$ above the fishing location. The River Kostonlammenoja had been previously known to harbour $M$. margaritifera, but the population was thought to have become extinct (fisheries planner Eero Moilanen, Metsähallitus, pers. comm.). The river was not surveyed conventionally after the electrofishing, but according to our results it still harbours M. margaritifera.

At the river level, no false negative classifications were obtained, and in 14 rivers all uninfected fish were classified correctly by each observer (Table 4). However, a false positive classification was obtained in five rivers (Table 4). In each of these cases, the total river-level naked-eye score was very low ( 0.07 to 0.40 on the 0 to 5 scale), and as earlier, any incorrect classification did not occur when the mean naked-eye score was higher than 0.5 (Table 4). However, among the revealed FPM rivers, the mean score was less than 0.5 in 2 of the 3 cases (Table 4).

Overall, by testing and applying the electrofishing method, 197 wild brown trout were examined microscopically for mussel infection, and only glochidia belonging to $M$. margaritifera were identified. The reason for the few false positive records remains unknown, but may be due to tumours or external debris present on the fish gills.

\section{DISCUSSION}

Electrofishing is the main standardized method for capturing small salmonids nondestructively in lotic systems (Hudy, 1985; Bohlin et al., 1989). The present results 
show that electrofishing also can be used to search for freshwater pearl mussel (Margaritifera margaritifera) populations, with moderate to high intensity of $M$. margaritifera infection being reliably seen quickly with the naked eye on the gills of stunned host fish. Results of this study also indicate that the quick naked-eye examination can provide a good estimate of the intensity of the infection, and thus give some indication of glochidial production capacity of the mussel population without disturbing the sensitive mussel bed itself, and without depleting the host fish population.

However, there are some limitations should be taken into account when applying the electrofishing method. First, the method requires electrofishing equipment and at least a two-person team. Second, the reliable applicability of the method is limited to the late part of the parasitic stage of $M$. margaritifera, as the results indicate that freshly attached glochidia of size only $70-80 \mu \mathrm{m}$ may not be reliably observed with the naked eye (Table 1). Thus, knowledge about the glochidial excystment time in the study area may help one to employ the electrofishing method at the right time, i.e. when glochidia are as large as possible but not yet detached from the fish. Unfortunately, this knowledge is not usually available when investigating unsurveyed rivers in remote areas, as in this study. We can, nonetheless, estimate that for example in the northern Europe the ideal time to examine salmonids for $M$. margaritifera infection is between spring and midsummer. Finally, the method seems to be most reliable when the number of glochidia per fish is more than 20 (Tables 1-3), although it is likely that with more experience the number of incorrect scores among fish of low numbers of glochidia (less than 20) would eventually decrease. It is also worth mentioning that if the number of mussels in a selected river is low, if reproduction in the population is not successful, or if the population occurs far below or far above the electrofishing site, the occurrence of glochidia and thus the mussel population may remain undetected.

Possible migration of salmonid hosts may potentially confound the observations. In the River Lukkarinoja, five brown trout were caught, but only one of them was infected by M. margaritifera (Table 4), and the mussel population was found a few kilometres above the electrofishing site. In this instance, it is likely that the infected fish had migrated to the fishing site from the mussel area. However, in general, juvenile brown 
trout - the most common host of M. margaritifera in many areas (Young and Williams, 1984a; Hastie and Young, 2001; Österling and Wengström, 2015) although several populations which use only salmon as their only host have also been reported (Karlsson et al., 2014) - tend not to move very far (Harcup et al., 1984; Olsson and Greenberg, 2004). Thus, one should particularly focus on catching juvenile salmonids when searching for M. margaritifera populations using the presented electrofishing method. It is also important to note that glochidia of $M$. margaritifera may move from the habitat of adult mussels, as well; it has been shown that unattached larvae can survive for at least 8 days under optimal conditions (Taskinen et al., 2011), and drift at least $500 \mathrm{~m}$ in a river and still remain infective (Hastie and Young, 2001). However, because glochidia only can move in a downstream direction, selecting a fishing site from downstream sections of potential mussel habitats would have a better chance of revealing $M$. margaritifera glochidia on fish hosts.

The limitations of the electrofishing method listed above also apply to the photoidentification method developed by Österling (2011), but with the photo-method it is possible to observe also the small, freshly attached M. margaritifera glochidia (Österling, 2011). However, observing M. margaritifera glochidia using only the naked eye takes less time and requires less equipment in the field than the photo-method. Furthermore, there is no need to install the metal spatula between the gill arches as used by Österling (2011), making the electrofishing method less intrusive to the fish. Some signs of minor spinal injuries in fish after electrofishing have been reported (Dalbey et al., 1996), but in the study of Österling (2011), no increased mortality among any of the treatment was observed. Also, for most electrofishing surveys, it is normal to anaesthetise fish and measure their length prior to release. If information pertaining to fish length is not needed for the glochidial examination, then the electrofishing method described in this study does not require anaesthetisation, given that the visual check takes only a few seconds and can be done immediately after the catch while the fish is still stunned. Consequently, the fish can be released instantly after the glochidial examination because there is no need for fish to recover from the anaesthetisation. Thus, the fish handling time in the current electrofishing method is lower than in typical electrofishing surveys. 
Despite the aforementioned limitations and a few false naked-eye classifications, the electrofishing method proved to be a practical method of surveying for freshwater pearl mussel populations. Among 40 study rivers in the River Iijoki catchment, brown trout were caught from 22 of them, and fish were found to harbour M. margaritifera infection in 3 rivers (Table 4). The occurrence of adult mussels was confirmed in 2 of these rivers, with the third river reportedly harbouring $M$. margaritifera population in the past but thought to have become extinct what it obviously is not. Thus, three new, potentially reproducing $M$. margaritifera populations were revealed in just in the first test of the method. Therefore, results of this study suggest that if salmonids with $M$. margaritifera glochidia are found, and especially if the fish or river level mean score of the observers is more than 0.5 using the naked-eye scoring system of the present study, one can get an indication that there is a robust, glochidium-producing freshwater pearl mussel population in the river. In addition, because the important role of mussels coming from their filtering and burrowing activity is recognized (e.g. Howard and Cuffey, 2006; Vaughn et al., 2008; Geist, 2010), they are especially the most important river ecosystems of high conservation value to be potentially discovered with the electrofishing method. Furthermore, the electrofishing method provides knowledge on the occurrence and the density of salmonids and other fish species in the selected rivers - valuable information that cannot be collected with the traditional mussel search methods. The quick glochidial examination would also be useful to incorporate within electrofishing and salmonid research, especially if the work is conducted in remote unsurveyed rivers - conjoining of two surveys into one provides better value for the work.

Whether the electrofishing method (or any traditional technique) is used, one cannot rule out the possibility of $M$. margaritifera being present in the river. Instead, the strength of the presented method is to find unknown populations of $M$. margaritifera potentially cost-effectively; indeed, a catch and quick assessment of only one fish may give an indication about the occurrence of the mussel in a river. The results also suggest a high repeatability of the naked-eye scoring technique, given that any statistical differences between the scores of the different observers were not found. Also, given 
that captured fish can be released after the quick examination, applying the presented electrofishing technique even to the smallest brooks with very low number of salmonids is not problem as the method does not threaten the fish populations - it is worth to note that fish were not released in this first application of the method to be able to test its reliability and effectiveness, and due to that the sample sizes in the present study had to keep low in the cases of wild fish.

No glochidia from mussels other than $M$. margaritifera were found in any of the fish captured during this study. It is, however, possible that other mussel species, like the duck mussel, Anodonta anatina, (Oulasvirta, 2011) can occasionally occur in the same river and thus simultaneously infect the same fish. However, when electrofishing is carried out between spring and midsummer, as suggested above, the probability of fish carrying $A$. anatina glochidia is negligible, given that $A$. anatina releases its larvae to water in early spring and the parasitic stage lasts only a few weeks (Jokela et al., 1991; Taskinen et al., 1997). The thick-shelled river mussel, Unio crassus, can also be found in rivers containing M. margaritifera (Zettler and Jueg, 2007; Zieritz et al., 2012), but salmonids are not suitable hosts for this species (Taeubert et al., 2012). Nonetheless, the electrofishing method could be useful in searching for other mussel species, too, especially ones which have relatively large glochidia, and in cases of simultaneous infections, the mussel species can be identified morphologically (Pekkarinen and Englund, 1995a, b; Pekkarinen and Valovirta, 1996) or using molecular techniques (Gerke and Tiedemann, 2001; Zieritz et al., 2012).

The current study area, the River Iijoki catchment altogether includes 1400 streams, with some of these streams being relatively dark, turbid or brown colored, hiding the mussels effectively and making it difficult to uncover populations of $M$. margaritifera using traditional sampling techniques. Furthermore, this catchment is a typical example of Finnish river systems, which together cover thousands of small rivers and streams and thus, probably many undiscovered $M$. margaritifera populations. Therefore, especially in that kind of catchments the electrofishing method described in this study may provide an effective means for searching for M. margaritifera, thus revealing its status and contributing to its conservation efforts. Although the presence of adult 
mussels must continue to be determined, probably with traditional methods, we propose that the electrofishing method can serve as a valuable instrument for finding undiscovered populations of freshwater pearl mussel - possibly as a first line exploratory tool in large unmapped drainages. Furthermore, the future electrofishing surveys in salmonid rivers of remote areas could combine two purposes; the main one on salmonids (i), and the added check of gills for glochidia (ii) - an approach that is advisable also in the sense of limited science funds.

\section{Acknowledgements}

We express our deepest gratitude to the local River Iijoki and mussel experts PirkkoLiisa Luhta and Eero Moilanen. We thank Olli Nousiainen and Tapani Säkkinen for assistance in electrofishing and microscopic examinations. Professor Dale D. Edwards, Dr. Peter Cosgrove and an anonymous reviewer kindly commented on the manuscript and checked the English. Thanks also to other comments from University of Jyväskylä staff. Financial support by the Doctoral Programme in Biological and Environmental Science of the University of Jyväskylä, EU Interreg IV A Nord Programme, Maj and Tor Nessling Foundation, Raija and Ossi Tuuliainen Foundation and the Academy of Finland enabled the study. We acknowledge the environmental authorities for permitting us the licenses (PPO-2008-L-709-254 and POPELY/513/07.01/2011) to conduct the study.

\section{References}

Álvarez-Claudio C, García-Rovés P, Ocharan R, Cabal JA, Ocharan FJ, Álvarez MA. 2000. A new record of the freshwater pearl mussel Margaritifera margaritifera L. (Bivalvia, Unionoida) from the River Narcea (Asturias, north-western Spain). Aquatic Conservation: Marine and Freshwater Ecosystems 10: 93-102.

Bauer G. 1986. The status of the freshwater pearl mussel Margaritifera margaritifera L. in the south of its European range. Biological Conservation 38: 1-9.

Bauer G. 1987a. Reproductive strategy of the freshwater pearl mussel Margaritifera margaritifera. Journal of Animal Ecology 56: 691-704. 
Bauer G. 1987b. The parasitic stage of the freshwater pearl mussel (Margaritifera margaritifera L.) III. Host relationships. Archiv für Hydrobiologie, Supplements 76: 413-423.

Bauer G. 1988. Threats to the freshwater pearl mussel Margaritifera margaritifera $\mathrm{L}$. in Central Europe. Biological Conservation 45: 239-253.

Bauer G, Vogel C. 1987. The parasitic stage of the freshwater pearl mussel (Margaritifera margaritifera L.) I. Host response to glochidiosis. Archiv für Hydrobiologie, Supplements 76: 393-402.

Bohlin T, Hamrin S, Heggberget TG, Rasmussen G, Saltveit SJ. 1989. Electrofishing tTheory and practise with special emphasis on salmonids. Hydrobiologia 173: 9-43. Cosgrove P, Hastie L, MacDougall K, Kelly A. 2007. Development of a remote, deepwater survey method for freshwater pearl mussels. Scottish Natural Heritage Commissioned Report No. 263 (ROAME No. F06AC606), Inverness, Scotland. Cosgrove PJ, Young MR, Hastie LC, Gaywood M, Boon, PJ. 2000. The status of the freshwater pearl mussel Margaritifera margaritifera Linn. in Scotland. Aquatic Conservation: Marine and Freshwater Ecosystems 10: 197-208.

Cuttelod A, Seddon M, Neubert E. 2011. European red list of non-marine molluscs. Luxembourg: Publications Office of the European Union.

Dalbey SR, McMahon TE, Fredenberg W. 1996. Effect of electrofishing pulse shape and electrofishing-induced spinal injury on long-term growth and survival of wild rainbow trout. North American Journal of Fisheries Management 16: 560-569.

Geist J. 2010. Strategies for the conservation of endangered freshwater pearl mussels (Margaritifera margaritifera L.): a synthesis of conservation genetics and ecology. Hydrobiologia 644: 69-88.

Geist J, Porkka M, Kuehn R. 2006. The status of host fish populations and fish species richness in European freshwater pearl mussel (Margaritifera margaritifera) streams. Aquatic Conservation: Marine and Freshwater Ecosystems 16: 251-266.

Gerke N, Tiedemann R. 2001. A PCR-based molecular identification key to the glochidia of European freshwater mussels (Unionidae). Conservation Genetics 2: 287289.

Harcup MF, Williams R, Ellis DM. 1984. Movements of brown trout, Salmo trutta L., in the River Gwyddon, South Wales. Journal of Fish Biology 24: 415-426. 
Hastie LC, Boon PJ. 2001. Does electrofishing harm freshwater pearl mussels? Aquatic Conservation: Marine and Freshwater Ecosystems 11: 149-152.

Hastie LC, Young MR. 2001. Freshwater pearl mussel (Margaritifera margaritifera) glochidiosis in wild and farmed salmonid stocks in Scotland. Hydrobiologia 445: 109119.

Helama S, Valovirta I. 2008. The oldest recorded animal in Finland: ontogenetic age and growth in Margaritifera margaritifera (L. 1758) based on internal shell increments. Memoranda Societatis pro Fauna et Flora Fennica 84: 20-30.

Howard JK, Cuffey KM. 2006. The functional role of native freshwater mussels in the fluvial benthic environment. Freshwater Biology 51: 460-474.

Hudy M. 1985. Rainbow trout and brook trout mortality from high voltage AC electrofishing in a controlled environment. North American Journal of Fisheries Management 5: 475-479.

IUCN Red List of Threatened Species. 2013. http://www.iucnredlist.org/ [05 March $2014]$

Jokela J, Valtonen ET, Lappalainen M. 1991. Development of glochidia of Anodonta piscinalis and their infection of fish in a small lake in northern Finland. Archiv für Hydrobiologie 120: 345-355.

Karlsson S, Larsen BM, Hindar K. 2014. Host-dependent genetic variation in freshwater pearl mussel (Margaritifera margaritifera L.). Hydrobiologia 735: 179-190.

Lydeard C, Cowie RH, Ponder WF, Bogan AE, Bouchet P, Clark SA, Cummings KS, Frest TJ, Gargominy O, Herbert DG et al. 2004. The global decline of nonmarine mollusks. BioScience 54: 321-330.

Olsson IC, Greenberg. 2004. Partial migration in a landlocked brown trout population. Journal of Fish Biology 65: 106-121.

Österling ME. 2011. Test and application of a non-destructive photo-method investigating the parasitic stage of the threatened mussel Margaritifera margaritifera on its host fish Salmo trutta. Biological Conservation 144: 2984-2990.

Österling EM, Wengström N. 2015. Test of the host fish species of a unionoid mussel: a comparison between natural and artificial encystment. Limnologica 50: 80-83. 
Ostrovsky AN, Popov IYüU. 2011. Rediscovery of the largest population of the freshwater pearl mussel (Margaritifera margaritifera) in the Leningrad oblast (northwest Russia). Aquatic Conservation: Marine and Freshwater Ecosystems 21: 113-121. Oulasvirta P. 2011. Distribution and status of the freshwater pearl mussel Margaritifera margaritifera in northern Fennoscandia. Toxicological \& Environmental Chemistry 93: 1713-1730.

Pekkarinen M, Englund VPM. 1995a. Description of unionacean glochidia in Finland, with a table aiding in their identification. Archiv für Hydrobiologie 134: 515-531. Pekkarinen M, Englund VPM. 1995b. Sizes of intramarsupial unionacean glochidia in Finland. Archiv für Hydrobiologie 134: 379-391.

Pekkarinen M, Valovirta I. 1996. Anatomy of the glochidia of the freshwater pearl mussel, Margaritifera margaritifera (L.). Archiv für Hydrobiologie 137: 411-423. Reis J. 2003. The freshwater pearl mussel [Margaritifera margaritifera (L.)] (Bivalvia, Unionoida) rediscovered in Portugal and threats to its survival. Biological Conservation 114: $447-452$.

Simon OP, Vaníčková I, Bílý M, Douda K, Patzenhauerová H, Hruška J, Peltánová A. 2015. The status of freshwater pearl mussel in the Czech Republic: $\underline{s} S e v e r a l$ successfully rejuvenated populations but the absence of natural reproduction. Limnologica 50: 11-20.

Strayer DL, Smith DR. 2003. A Guide to Sampling Freshwater Mussel Populations. American Fisheries Society Monograph 8: Bethesda, Maryland. Taskinen J, Mäkelä T, Valtonen ET. 1997. Exploitation of Anodonta piscinalis (Bivalvia) by trematodes: parasite tactics and host longevity. Annales Zoologici Fennici 34: $37-46$.

Taskinen J, Berg P, Saarinen-Valta M, Välilä S, Mäenpää E, Myllynen K, Pakkala J. 2011. Effect of $\mathrm{pH}$, iron and aluminum on survival of early life history stages of the endangered freshwater pearl mussel, Margaritifera margaritifera. Toxicological \& Environmental Chemistry 93: 1764-1777.

Taeubert J-E, Gum B, Geist J. 2012. Host-specificity of the endangered thick-shelled river mussel (Unio crassus, Philipsson 1788) and implications for conservation. Aquatic Conservation: Marine and Freshwater Ecosystems 22: 36-46. 
Varandas S, Lopes-Lima M, Teixeira A, Hinzmann M, Reis J, Cortes R, Machado J, Sousa R. 2013. Ecology of southern European pearl mussels (Margaritifera margaritifera): first record of two new populations on the rivers Terva and Beça (Portugal). Aquatic Conservation: Marine and Freshwater Ecosystems 23: 374-389. Vaughn CC, Nichols SJ, Spooner DE. 2008. Community and foodweb ecology of freshwater mussels. Journal of the North American Benthological Society 27: 409-423. Williams JD, Warren Jr. ML, Cummings KS, Harris JL, Neves RJ. 1993. Conservation status of freshwater mussels of the United States and Canada. Fisheries 18: 6-22. Young MR, Williams JC. 1983a. Redistribution and local recolonisation by the freshwater pearl mussel Margaritifera margaritifera (L.). Journal of Conchology $\mathbf{3 1}$ : $225-234$.

Young M, Williams J. 1983b. The status and conservation of the freshwater pearl mussel Margaritifera margaritifera Linn. in Great Britain. Biological Conservation 25: $35-52$.

Young M, Williams J. 1984a. The reproductive biology of the freshwater pearl mussel Margaritifera margaritifera (LINN.) in Scotland I. Field studies. Archiv für Hydrobiologie 99: 405-422.

Young M, Williams J. 1984b. The reproductive biology of the freshwater pearl mussel Margaritifera margaritifera (LINN.) in Scotland II. Laboratory studies. Archiv für Hydrobiologie 100: 29-43.

Zettler ML, Jueg U. 2007. The situation of the freshwater mussel Unio crassus (Philipsson, 1788) in north-east Germany and its monitoring in terms of the EC Habitats Directive. Mollusca 25: 165-174.

Zieritz A, Gum B, Kuehn R, Geist J. 2012. Identifying freshwater mussels (Unionoida) and parasitic glochidia larvae from host fish gills: a molecular key to the North and Central European species. Ecology and Evolution 2: 740-750.

Ziuganov V, San Miguel E, Neves RJ, Longa A, Fernández C, Amaro R, Beletsky V, Popkovitch E, Kaliuzhin S, Johnson T. 2000. Life span variation of the freshwater pearl shell: a model species for testing longevity mechanisms in animals. AMBIO: A Journal of the Human Environment 29: 102-105. 
Table 1. Naked-eye classifications (infected or non-infected by M. margaritifera) and microscopic counts for number of glochidia, with fish and glochidia lengths, for brown trout individuals electrofished from the Rivers Jukuanoja and Koivuoja between June and August 2011. Incorrect naked-eye classifications are marked with* and the fish with freshly attached small glochidia with a border lined box.

\begin{tabular}{|c|c|c|c|c|c|c|c|c|c|}
\hline \multicolumn{5}{|c|}{ The River Jukuanoja } & \multicolumn{5}{|c|}{ The River Koivuoja } \\
\hline Date & $\begin{array}{l}\text { Fish length } \\
(\mathrm{mm})\end{array}$ & $\begin{array}{c}\text { Naked-eye } \\
\text { classification }\end{array}$ & $\begin{array}{c}\text { Number } \\
\text { of glochidia }\end{array}$ & $\begin{array}{c}\text { Mean length } \pm \text { S.E. } \\
\text { of glochidia }(\mu \mathrm{m})\end{array}$ & Date & $\begin{array}{l}\text { Fish length } \\
(\mathrm{mm})\end{array}$ & $\begin{array}{c}\text { Naked-eye } \\
\text { classification }\end{array}$ & $\begin{array}{c}\text { Number } \\
\text { of glochidia }\end{array}$ & $\begin{array}{l}\text { Mean length } \pm \text { S.E. } \\
\text { of glochidia }(\mu \mathrm{m})\end{array}$ \\
\hline \multirow[t]{5}{*}{ June 9} & 77 & inf. & 176 & $291 \pm 9.1$ & June 9 & 134 & inf. & 1112 & $289 \pm 10.1$ \\
\hline & 109 & inf. & 165 & $250 \pm 9.6$ & & 151 & inf. & 67 & $272 \pm 9.9$ \\
\hline & 147 & inf. & 241 & $258 \pm 9.1$ & & 113 & inf. & 558 & $287 \pm 10.9$ \\
\hline & 77 & non-inf. & 0 & & & 160 & inf. & 1674 & $286 \pm 7.4$ \\
\hline & 78 & inf. & 105 & $247 \pm 8.0$ & & & & & \\
\hline \multirow[t]{5}{*}{ June 27} & 94 & inf. & 16 & $319 \pm 9.4$ & June 28 & 162 & non-inf. $*$ & 3 & $333 \pm 36.5$ \\
\hline & 132 & inf. & 1460 & $353 \pm 9.6$ & & 77 & inf. & 108 & $357 \pm 10.1$ \\
\hline & 110 & inf. & 406 & $330 \pm 9.0$ & & 139 & non-inf. * & 19 & $363 \pm 11.7$ \\
\hline & 90 & inf. & 126 & $330 \pm 11.6$ & & 138 & non-inf. * & 1 & 316 \\
\hline & & & & & & 97 & non-inf. & 0 & \\
\hline \multirow[t]{5}{*}{ July 20} & 115 & non-inf. * & 11 & $296 \pm 8.0$ & July 21 & 158 & non-inf. * & 1 & 456 \\
\hline & 112 & inf. & 6 & $392 \pm 18.5$ & & 169 & non-inf. * & 1 & 439 \\
\hline & 168 & non-inf. & 0 & & & 86 & non-inf. & 0 & \\
\hline & 54 & non-inf. & 0 & & & 146 & non-inf. & 0 & \\
\hline & 150 & inf. & 128 & $395 \pm 9.9$ & & & & & \\
\hline \multirow[t]{4}{*}{ August 2} & 216 & non-inf. & 0 & & August 3 & 138 & non-inf. & 0 & \\
\hline & 112 & non-inf. & 0 & & & 150 & non-inf. & 0 & \\
\hline & 63 & non-inf. & 0 & & & 157 & non-inf. & 0 & \\
\hline & 59 & non-inf. & 0 & & & 106 & non-inf. & 0 & \\
\hline \multirow[t]{2}{*}{ August 31} & 121 & non-inf. * & 16 & $74 \pm 6.3$ & August 31 & 148 & non-inf. & 0 & \\
\hline & 126 & non-inf. * & 265 & $81 \pm 2.9$ & & 143 & non-inf. & 0 & \\
\hline
\end{tabular}




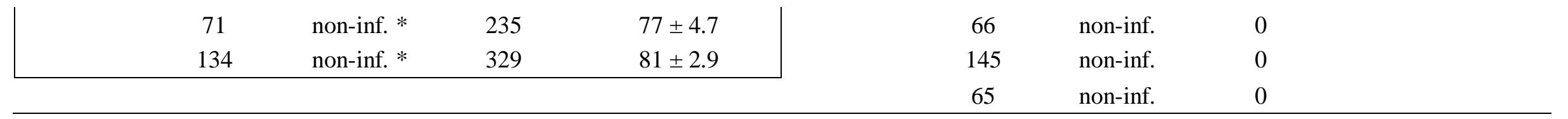

Table 2. Naked-eye scores for intensity (from $0=$ no glochidia to $5=$ very high number of glochidia, - = no score) of $M$. margaritifera infection by independent observers (O1, O2, O3), with mean of the scores, and microscopic counts for number of glochidia, with fish and glochidia lengths, for brown trout individuals electrofished from the Rivers Majovanoja and Pahkaoja between June 3 and 6, 2012 and 2013. Incorrect naked-eye classifications are marked with *. Association between the means of the naked-eye scores and microscopic counts was highly significant (see Results).

\begin{tabular}{|c|c|c|c|c|c|c|c|c|c|c|c|c|c|c|}
\hline \multirow[b]{3}{*}{ Year } & \multicolumn{7}{|c|}{ The River Majovanoja } & \multicolumn{7}{|c|}{ The River Pahkaoja } \\
\hline & \multirow{2}{*}{$\begin{array}{l}\text { Fish length } \\
\text { (mm) }\end{array}$} & \multicolumn{4}{|c|}{ Naked-eye scores } & \multirow{2}{*}{$\begin{array}{c}\text { Number } \\
\text { of glochidia }\end{array}$} & \multirow{2}{*}{$\begin{array}{l}\text { Mean length } \pm \text { S.E. } \\
\text { of glochidia }(\mu \mathrm{m})\end{array}$} & \multirow{2}{*}{$\begin{array}{l}\text { Fish length } \\
\text { (mm) }\end{array}$} & \multicolumn{4}{|c|}{ Naked-eye scores } & \multirow{2}{*}{$\begin{array}{l}\text { Number } \\
\text { of glochidia }\end{array}$} & \multirow{2}{*}{$\begin{array}{c}\text { Mean length } \pm \text { S.E. } \\
\text { of glochidia }(\mu \mathrm{m})\end{array}$} \\
\hline & & $\mathrm{O} 1$ & $\mathrm{O} 2$ & $\mathrm{O} 3$ & Mean & & & & O1 & $\mathrm{O} 2$ & $\mathrm{O} 3$ & Mean & & \\
\hline \multirow[t]{5}{*}{2012} & 69 & $0 *$ & 1 & $0 *$ & 0.33 & 4 & $219 \pm 8.8$ & 75 & 1 & 1 & 1 & 1.00 & 14 & - \\
\hline & 68 & 3 & 3 & 2 & 2.67 & 141 & $202 \pm 26.3$ & 122 & 3 & 3 & 2 & 2.67 & 399 & - \\
\hline & 70 & 3 & 3 & 4 & 3.33 & 143 & $246 \pm 17.5$ & 92 & 1 & 1 & 1 & 1.00 & 23 & - \\
\hline & & & & & & & & 57 & 0 & $1 *$ & 0 & 0.33 & 0 & \\
\hline & & & & & & & & 52 & 0 & $1 *$ & 0 & 0.33 & 0 & \\
\hline \multirow[t]{3}{*}{2013} & 138 & 2 & 1 & - & 1.50 & 1 & 228 & 74 & 2 & 1 & - & 1.50 & 23 & $233 \pm 7.9$ \\
\hline & 121 & $1 *$ & 0 & - & 0.50 & 0 & & & & & & & & \\
\hline & 72 & 5 & 5 & - & 5.00 & 387 & $296 \pm 7.1$ & & & & & & & \\
\hline Mean & & 2.33 & 2.17 & 2.00 & 2.20 & 113 & & & 1.17 & 1.33 & 0.80 & 1.12 & 77 & \\
\hline
\end{tabular}


Table 3. Naked-eye scores for intensity (from $0=$ no glochidia to $5=$ very high number of glochidia) of $M$. margaritifera infection by two independent observers $(\mathrm{O} 1, \mathrm{O} 2)$, with mean of the scores, and microscopic counts for numbers of glochidia, with fish and glochidia lengths, in brown trout exposed to M. margaritifera glochidia in laboratory. In addition to these 12 fish, there were 28 other fish inspected, with no glochidia found and having correctly scored as 0 by both observers. The exposure took place in September 19 2014, and fish were scored on July 13 2015. Incorrect naked-eye classifications are marked with *. Association between the means of the naked-eye scores and microscopic counts was highly significant (see Results).

\begin{tabular}{|c|c|c|c|c|c|c|}
\hline \multicolumn{2}{|r|}{ Fish } & \multicolumn{3}{|c|}{ Naked-eye scores } & \multirow{2}{*}{$\begin{array}{l}\text { Number } \\
\text { of glochidia }\end{array}$} & \multirow{2}{*}{$\begin{array}{l}\text { Mean length } \pm \text { S.E. } \\
\text { of glochidia }(\mu \mathrm{m})\end{array}$} \\
\hline No. & length $(\mathrm{mm})$ & $\mathrm{O} 1$ & $\mathrm{O} 2$ & Mean & & \\
\hline 1 & 114 & 5 & 5 & 5.00 & 1669 & $405 \pm 6.8$ \\
\hline 2 & 118 & 5 & 4 & 4.50 & 1459 & $368 \pm 10.3$ \\
\hline 3 & 109 & 5 & 4 & 4.50 & 1290 & - \\
\hline 4 & 120 & 4 & 4 & 4.00 & 908 & $394 \pm 6.9$ \\
\hline 5 & 126 & 4 & 4 & 4.00 & 782 & $396 \pm 6.5$ \\
\hline 6 & 121 & 4 & 4 & 4.00 & 735 & $409 \pm 5.4$ \\
\hline 7 & 115 & 5 & 3 & 4.00 & 596 & - \\
\hline 8 & 121 & 2 & 2 & 2.00 & 184 & $340 \pm 10.8$ \\
\hline 9 & 121 & 1 & 1 & 1.00 & 71 & $361 \pm 9.0$ \\
\hline 10 & 128 & 1 & 1 & 1.00 & 47 & $339 \pm 10.6$ \\
\hline 11 & 109 & $0 *$ & $0 *$ & 0 & 1 & - \\
\hline 12 & 133 & 0 & $1 *$ & 0.5 & 0 & \\
\hline
\end{tabular}

Table 4. The 40 rivers electrofished in June 3-14 2012-2013 with total fishing effort (f) and numbers of brown trout caught ( $\mathrm{N}_{\text {fish}}$ ). The mean naked-eye scores for intensity (from $0=$ no glochidia to $5=$ very high number of glochidia, $-=$ no score) of $M$. margaritifera infection in the fish are shown by each 
observer $(\mathrm{O} 1, \mathrm{O} 2, \mathrm{O} 3)$ and per each river, as well as both number of infected fish ( $\left.\mathrm{N}_{\text {infected }}\right)$ and prevalence and intensity of infection observed in microscopic examination. Rivers with fish confirmed to harbour M. margaritifera infection, i.e. the 'new' M. margaritifera populations, are marked with *.

\begin{tabular}{|c|c|c|c|c|c|c|c|c|c|c|c|}
\hline \multirow[b]{2}{*}{ No. } & \multirow[b]{2}{*}{ River } & \multirow[b]{2}{*}{ Fishing year } & \multirow[b]{2}{*}{$f(\min )$} & \multirow[b]{2}{*}{$\mathrm{N}_{\text {fish }}$} & \multicolumn{4}{|c|}{ Naked-eye scores } & \multicolumn{3}{|c|}{ Laboratory examination } \\
\hline & & & & & $\mathrm{O} 1$ & $\mathrm{O} 2$ & $\mathrm{O} 3$ & Mean & $\mathrm{N}_{\text {infected }}$ & Prevalence $(\%)$ & Mean intensity \pm S.E. \\
\hline 1 & Aimojoki & $2012 \& 2013$ & 165 & 9 & 0 & 0 & - & 0 & 0 & 0 & \\
\hline 2 & Elehvänoja & 2012 & 45 & 5 & 0 & 0 & - & 0 & 0 & 0 & \\
\hline 3 & Hietajoki 1 & 2013 & 60 & 5 & 0.20 & 0.60 & - & 0.40 & 0 & 0 & \\
\hline 4 & Jaaskamonoja & $2012 \& 2013$ & 195 & 9 & 0 & 0 & - & 0 & 0 & 0 & \\
\hline 5 & Karhuoja & 2012 & 45 & 1 & 0 & 0 & 0 & 0 & 0 & 0 & \\
\hline 6 & Kisosjoki $*$ & 2012 & 135 & 19 & 0.05 & 0.21 & 0.11 & 0.12 & 3 & 16 & $3.0 \pm 0.6$ \\
\hline 7 & Koiraoja & 2012 & 90 & 2 & 0 & 0 & - & 0 & 0 & 0 & \\
\hline 8 & Kostonlammenoja * & 2013 & 135 & 14 & 0.21 & 0.07 & - & 0.14 & 6 & 43 & $12.7 \pm 4.1$ \\
\hline 9 & Kutinjoki & $2012 \& 2013$ & 180 & 5 & 0 & 0 & - & 0 & 0 & 0 & \\
\hline 10 & Kylmävaaranpuro & 2012 & 30 & 6 & 0 & 0 & - & 0 & 0 & 0 & \\
\hline 11 & Latvajoki 1 & 2012 & 120 & 5 & 0.20 & 0 & 0 & 0.07 & 0 & 0 & \\
\hline 12 & Lohioja & 2013 & 60 & 2 & 0 & 0 & - & 0 & 0 & 0 & \\
\hline 13 & Loukusanjoki & $2012 \& 2013$ & 120 & 8 & 0 & 0 & 0.20 & 0.07 & 0 & 0 & \\
\hline 14 & Lukkarinoja * & 2012 & 60 & 5 & 0.80 & 0.60 & 0.80 & 0.73 & 1 & 20 & 183 \\
\hline 15 & Ohtaoja & 2013 & 90 & 5 & 0 & 0.20 & - & 0.10 & 0 & 0 & \\
\hline 16 & Oudonjoki & 2012 & 30 & 4 & 0 & 0 & - & 0 & 0 & 0 & \\
\hline 17 & Paljakkaoja & 2012 & 60 & 5 & 0.20 & 0 & 0 & 0.07 & 0 & 0 & \\
\hline 18 & Pirinoja & 2012 & 45 & 5 & 0 & 0 & 0 & 0 & 0 & 0 & \\
\hline 19 & Rääpysoja & $2012 \& 2013$ & 80 & 4 & 0 & 0 & - & 0 & 0 & 0 & \\
\hline 20 & Siiranjoki & $2012 \& 2013$ & 195 & 13 & 0 & 0 & - & 0 & 0 & 0 & \\
\hline 21 & Tutuoja & 2012 & 55 & 5 & 0 & 0 & 0 & 0 & 0 & 0 & \\
\hline 22 & Ylä-Haapuanoja & 2013 & 90 & 5 & 0 & 0 & - & 0 & 0 & 0 & \\
\hline
\end{tabular}




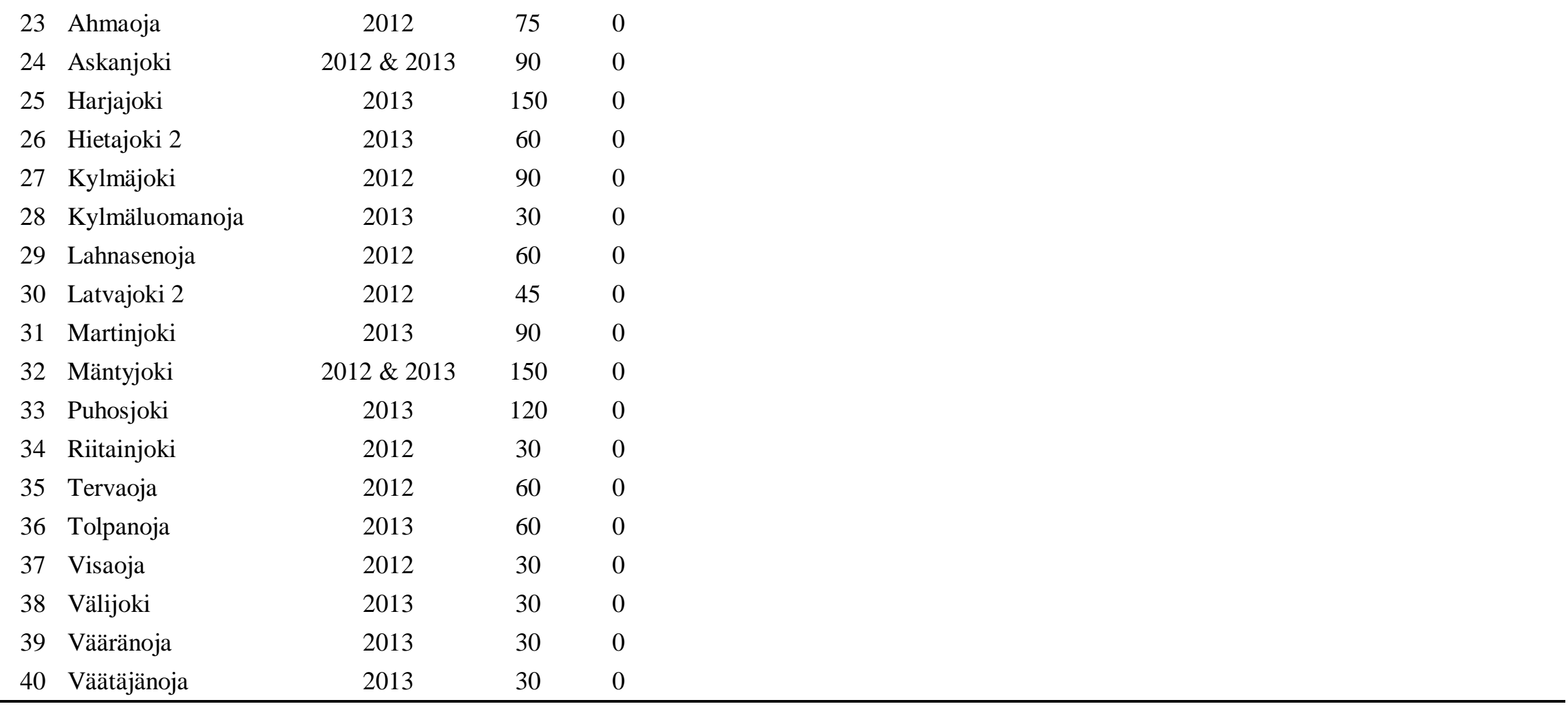


Figure 1. Map of the River Iijoki drainage with its main tributaries. The star symbols J, K, M and P depict the locations of the Rivers Jukuanoja, Koivuoja, Majovanoja and Pahkaoja, respectively, where the electrofishing method was tested in 2011-2012. L is the River Livojoki, where M. margaritifera glochidia were collected for laboratory study. The 40 dots are the survey points of the rivers where the method was applied in 2012-2013; the Rivers Kisosjoki, Kostonlammenoja and Lukkarinoja are marked as N1, N2 and N3, respectively. The inset map of northern Europe shows Finland in grey and the River Iijoki catchment in black. For conservation of M. margaritifera, the exact coordinates for the study rivers are not given, but they are available from the authors.

Figure 2. Categories 1, 2, 3, 4 and 5, respectively, for the intensity of M. margaritifera infection on gills of brown trout shown in microscopic photos. Category 0 indicates that any larva was not observed on the gills. 


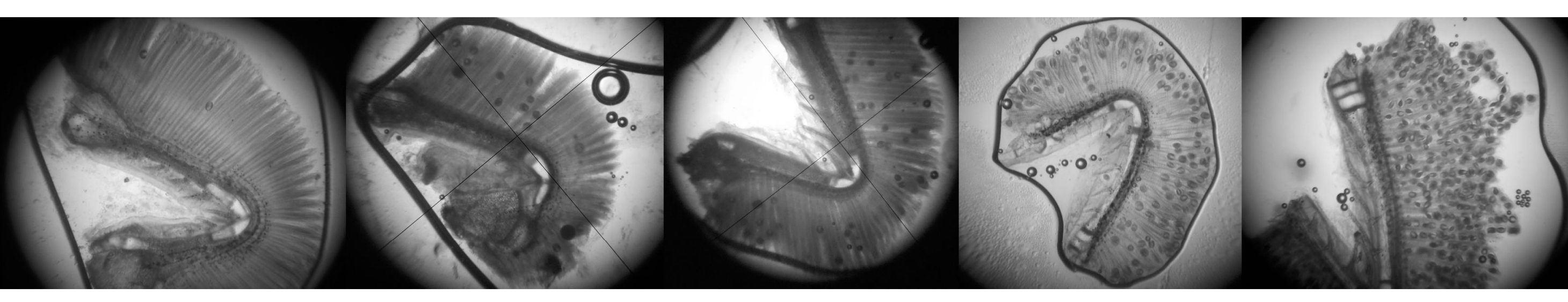

